\title{
Trasversus abdomini release, botulinum, pneumoperitoneum: are they sufficient support in the treatment of complex incisional hernia?
}

\author{
G. Campanelli ${ }^{1}$
}

Published online: 18 November 2021

(c) The Author(s), under exclusive licence to Springer-Verlag France SAS, part of Springer Nature 2021

There is no doubt that complex abdominal wall repair procedures constitute major surgery. Real loss of substance, deep infections, and multiple relapses, especially in patients with comorbidities, can result in highly complex situations in different surgical stages: presurgical optimisation, the surgery itself, and peri- and post-surgical management.

In addition to proving highly challenging even for the most expert surgeons, the management of these situations can be extremely costly for departments and hospitals alike. For all these reasons, it now seems inevitable that these cases will increasingly be concentrated in specialist centres that, in addition to being equipped with indisputable specific anatomical knowledge, specific surgical experience and indepth understanding of these problems, are used to dealing with complex situations, and are also well resourced and efficiently run.

It is now clear that not all hospital surgery departments can or should take these patients.

In line with what we have seen in the fields of pancreatic and hepatobiliary surgery, specialist centres of reference are now emerging also for patients requiring surgery for reconstruction of complex abdominal wall defects.

An important initiative in this regard, launched by the European Commission and, in particular the UEMS, is the introduction of a European Board of Surgical
Qualification (EBSQ) examination in abdominal wall surgery.

The first exam session was held during the recent HERNIA 2021 meeting in Copenhagen, and may be seen as the first step towards European certification in this specialty field, which in turn is the natural prelude to the establishment of dedicated centres of excellence.

Many of the articles in this issue of Hernia come from outstanding and internationally renowned centres and focus on precisely the difficult situations mentioned above.

Giampiero Campanelli (Editor-in-Chief)

\section{Note from the Editors}

As the current year draws to a close, we are delighted to be able to share with you the results set out in the tables below, which show how our prestigious journal has gone from strength to strength over the past 3 years.

We extend our grateful thanks to all the members of the International Advisory Board, our section editors, reviewers, authors and readers.

Giampiero Campanelli, Editor-in-Chief, and the Associate Editors Jie Chen, Diego Cuccurullo, Namir Katkhouda, Davide Lomanto, Rachid Sani

G. Campanelli

hernia.editorialoffice@gmail.com

1 Gruppo Ospedaliero San Donato, University of Insubria, Milan, Italy 

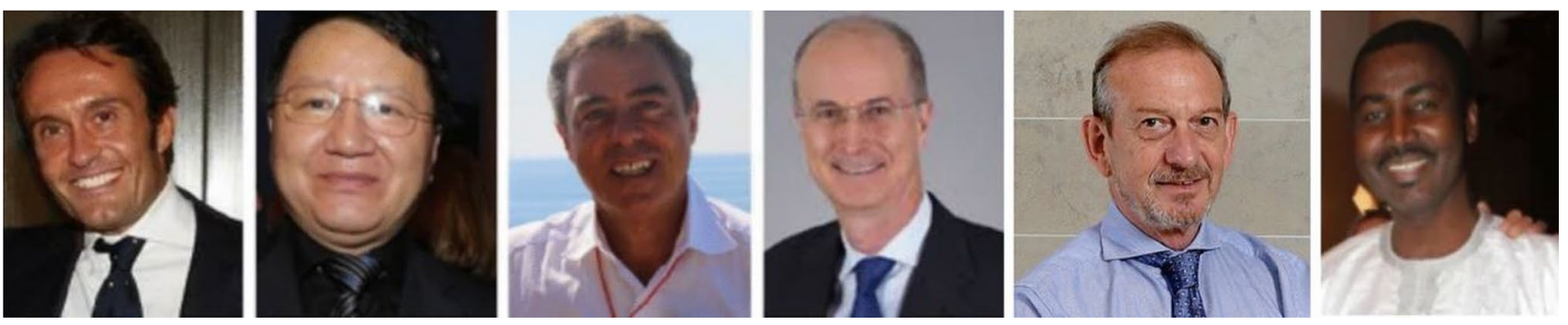

Tables 1 and 2.

Table 1 Journal's performance in the latest 3 years

\begin{tabular}{llll}
\hline Submissions (12 months from Nov to Nov) & 2019 & 2020 & 2021 \\
\hline Total submitted & 565 & 708 & 613 \\
Total decisioned & 510 & 662 & 547 \\
Accept & 179 & 209 & 155 \\
Reject & 326 & 448 & 377 \\
Withdrawn & 5 & 16 & 15 \\
Acceptance rate & $35 \%$ & $32 \%$ & $29 \%$ \\
Rejection rate & $65 \%$ & $68 \%$ & $71 \%$ \\
\hline Average turnaround times & 2019 & 2020 & 2021 \\
\hline Average days to first decision & 37.3 & 22.4 & 23.9 \\
\hline
\end{tabular}

Table 2 Geographical origin of the manuscripts

\begin{tabular}{lll}
\hline$n$ & Country & Submitted \\
\hline 1 & United States & 91 \\
2 & China & 76 \\
3 & India & 38 \\
4 & United Kingdom & 38 \\
5 & Turkey & 32 \\
6 & Italy & 30 \\
7 & Spain & 26 \\
8 & Japan & 25 \\
9 & Brazil & 22 \\
10 & Germany & 17 \\
11 & The Netherlands & 16 \\
12 & Greece & 15 \\
13 & France & 14 \\
14 & Australia & 15 \\
15 & Canada & 12 \\
16 & Denmark & 12 \\
17 & Singapore & 10 \\
18 & Taiwan & 9 \\
19 & Sweden & 8 \\
20 & Switzerland & 8 \\
\hline & &
\end{tabular}

Table 2 (continued)

\begin{tabular}{lll}
\hline$n$ & Country & Submitted \\
\hline 21 & Iran, Islamic Republic of & 7 \\
22 & Israel & 7 \\
23 & Korea, Republic of & 7 \\
24 & Egypt & 6 \\
25 & Belgium & 5 \\
26 & Colombia & 5 \\
27 & Finland & 5 \\
28 & Austria & 5 \\
29 & Romania & 4 \\
30 & Czech Republic & 3 \\
31 & Ireland & 3 \\
32 & Lithuania & 3 \\
33 & Mexico & 3 \\
34 & Poland & 3 \\
35 & Latvia & 2 \\
36 & Nigeria & 2 \\
37 & Russian Federation & 2 \\
38 & Serbia & 2 \\
39 & Thailand & 2 \\
40 & Chile & 1 \\
\hline & &
\end{tabular}


Table 2 (continued)

\begin{tabular}{lll}
\hline$n$ & Country & Submitted \\
\hline 41 & Cyprus & 1 \\
42 & Ethiopia & 1 \\
43 & Gabon & 1 \\
44 & Ghana & 1 \\
45 & Hong Kong & 1 \\
46 & Indonesia & 1 \\
47 & Malaysia & 1 \\
48 & New Zealand & 1 \\
49 & Portugal & 1 \\
\hline
\end{tabular}

Conflict of interest Not applicable.

Ethical approval Not applicable.

Human and animal rights Not applicable.
Table 2 (continued)

\begin{tabular}{lll}
\hline$n$ & Country & Submitted \\
\hline 50 & Saudi Arabia & 1 \\
\hline 51 & Tunisia & 1 \\
52 & United Arab Emirates & 1 \\
53 & Viet Nam & 1 \\
54 & Argentina & 7 \\
55 & Algeria & 2 \\
\hline
\end{tabular}

54 countries of all continents

Informedconsent Not applicable.

Publisher's Note Springer Nature remains neutral with regard to jurisdictional claims in published maps and institutional affiliations. 